\title{
Toward an Integrated Sustainability Assessment in Through-life Engineering Services
}

\author{
Maryam Farsi ${ }^{\mathrm{a}^{*}}$, John Ahmet Erkoyuncu ${ }^{\mathrm{a}}$ \\ ${ }^{a}$ Through-life Engineering Services Centre, Cranfield University, Cranfield, MK43 OAL, UK \\ *Corresponding author. Tel.: +44-123-475-0111; E-mail address: maryam.farsi@cranfield.ac.uk
}

\begin{abstract}
Through-life Engineering Services (TES) is comprised of develop, prepare, utilize and retire phases for complex engineering assets with a focus on maximizing their availability, predictability and reliability at the lowest possible life-cycle cost. TES employs a set of technologies and solutions to improve asset performance efficiently. On the other hand, optimal solutions for minimizing waste in terms of service time and resources is crucial for designing the right service at the right time. Thereby, specifying the possible TES opportunities within the economic, social and environmental sustainability dimensions can be an added value across different manufacturing sectors when deploying TES. However, due to the complexities and immensity of TES approaches, it is challenging to perceive such opportunities. To this end, the existing literature is limited to the effect of TES on economic sustainability and mostly focuses on investigating how TES has modified the service design to improve productivity and profitability. However, a comprehensive study on integrated sustainability has not been yet conducted. This paper presents a holistic view of the potential TES opportunities associated with the sustainability triple bottom line following a systematic review of empirical and theoretical advancements and methodological approaches in the literature. The outcome from this research raises the awareness of TES contribution in the design of sustainable service solutions and technologies, and offers a benchmark and reference point for future research in the field. Finally, this paper provides a set of recommendations that call for the further development of an integrated sustainability assessment framework for TES.
\end{abstract}

Keywords: Through-life Engineering Services (TES); Sustainability; Product life-cycle; Integrated Sustainability Assessment; Sustainable development; Systematic Review

\section{Introduction}

The concept of sustainable development was first introduced by Brundtland in 1987 [1] as a "development that meets the needs of the present without compromising the ability of future generations to meet their own needs". In 1994, Elkington [2] highlighted that sustainable development for businesses could be achieved by cooperating with their suppliers, customers stakeholders and competitors, leading to a win-win business strategy. Later, he introduced the concept of 'Triple Bottom Line' as the economic, social and environmental pillars of sustainability [3]. He argued that sustainability is a nonlinear game for businesses which can only be reached through an effective, long-term interlink between TBL elements. Since the late 90s, the 'Integrated Sustainability Assessment (ISA)' has been implemented as an effective approach to identify and evaluate the effects of parameters, functions, policies and regulations on sustainability. In this regard, Environmental Impact Assessment (EIA) looks at the environmental aspects. Whereas, Strategic Environmental Assessment (SEA) focuses on economic and social features in ISA. Different approaches, tools and methodologies for EIA and SEA are presented and discussed in $[4,5]$. In general, the environmental assessment evaluates energy and material consumption, and carbon, atmospheric and waterborne emissions. It aims to minimize the need for water, fossil resources and natural gases. The economic assessment estimates the prosperity and profitability of organizations and individuals. Finally, the social assessment measures the social and sociological impacts of organizations and individuals [6].

In 2017, the Aerospace Technology Institute published a technical report on 'Through-life Engineering Services Technology Strategy for the UK aerospace sector [7]. TES is described as a set of engineering knowledge, tools and technologies to ensure assets are designed, developed, operated and serviced, and phased out at the optimum whole-life cost [8]. The report highlighted the significance of TES to the UK OEMs, supply chain companies and repair, maintenance and overhaul (RMO) providers with a view to support the sector's capability for advanced TES provision. It is estimated that the through-life support opportunities associated with the growing number of aircraft would be over US $\$ 2$ trillion [7]. Thereby, TES plays a crucial role throughout the assets' life-cycle and has a significant impact on assets' availability, reliability, quality and cost. Currently, TES implications and benefits mostly focus on economic impacts such as reducing 
the design and maintenance costs, reducing the rework at both design and manufacturing stages, spares optimization, and improving products availability, reliability, and predictability. Nonetheless, these impacts could have secondary effects on a product life-cycle that can positively influence the environment by reducing material usage and waste, reducing events and activities cycle-times throughout the life-cycle, improving fuel efficiency, and extending product lifetime. Some of the other possible sustainability metrics that can be applied to TES in relation to the environmental metrics can be human health outcomes, natural resource consumption, energy consumption and netzero carbon. Moreover, the social impacts can be working condition, health and safety, culture, governance, socio-economic repercussions, feedback, fair salary, working hours, equal opportunities, security, and consumer privacy [9]. Life-cycle cost (LCC) of products and services, value creation, and profitability are the key metrics to assess the impact of economic sustainability [10].

Nevertheless, the existing technology challenges regarding modelling and evaluating environmental footprint and energy consumptions, together with some of the cultural and policy barriers, restrict TES from implementing an ISA throughout the product life-cycle for effectively deploying sustainable design, service, and estimation of remaining useful (and sustainable) life [11]. To enhance the ISA implementation in TES, this paper addresses the research question of "What are the sustainability opportunities including social, economic and environmental aspects in TES and throughout the product life-cycle?". Thus, this research contributes to knowledge by a thorough evaluation of 'sustainable development in product life-cycle' and presents a holistic view of the potential TES opportunities associated with ISA through a systematic review.

This paper is structured as follows: Section 2 . presents the systematic review methodology to carry out the research. Section 3. discusses the relevant literature on sustainability and product life-cycle. The proposed mind map of TES opportunities in integrated sustainability is presented in Section 4. Section 5 presents the concluding remarks and the recommendation for future research.

\section{Research Methodology}

This study adopted the systematic review methodology to examine existing literature related to 'sustainable development in product life-cycle'. The Scopus research repository was searched with no lower time-limit and up to June 2020. The search process was impacted by several criteria, such as document type, keywords, and language. The keywords used to perform the search activity were initially set as 'sustainable development' or 'sustainability' and 'product life-cycle'. Moreover, to frame and scope the study, a set of inclusion and exclusion criteria were adopted. The criteria used for entering the systematic review were a) journal articles, conference papers, and book chapter, and b) papers that offered original analysis and provided results. The criteria used for excluding a paper from the study are as follows a) industrial reports, c) studies falling outside the subject area, and d) papers that largely had a focus on logistics and supply chains. The following keyword string was therefore used to define the initial database of documents:

"sustainable development" in "product life-cycle" AND (LIMIT-TO (DOCTYPE, "ar") OR LIMITTO (DOCTYPE, "cp") OR LIMIT-TO (DOCTYPE, "ch")) AND (LIMIT-TO (LANGUAGE, "English")) AND (LIMIT-TO ( EXACTKEYWORD, "Sustainable Development") OR LIMIT-TO (EXACTKEYWORD, "Sustainability")) .

In order to filter down the identified studies, the PRISMA 2009 flow diagram and guidelines were used. In the identification stage, the search yielded 1,468 documents. Subsequently, in the screening stage, the title and abstract of documents were examined in order to determine their relevance to TES. For instance, many of the articles presented and discussed sustainability in construction, agriculture or software development sectors. This caused the exclusion of 638 documents.

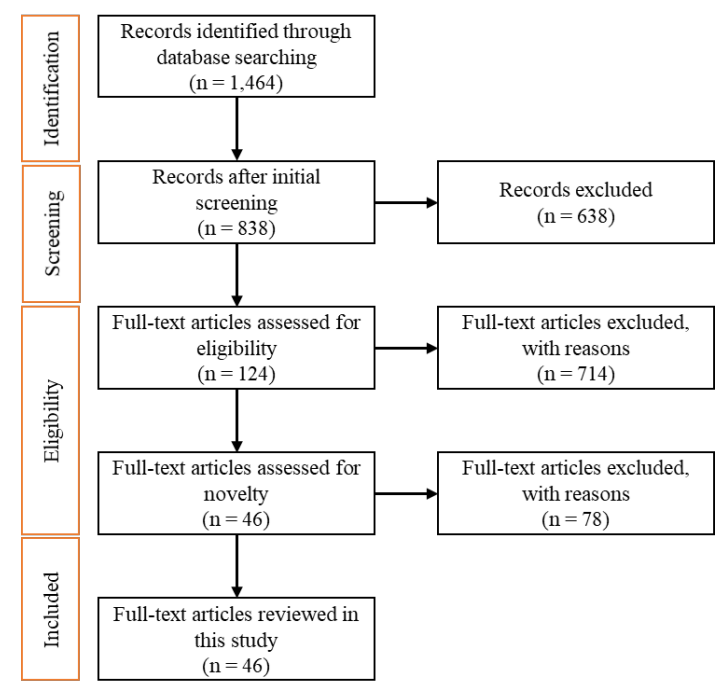

Figure 1: PRISMA flow diagram for selecting literature from the Scopus index

Next, the full-text articles were manually reviewed and assessed for their eligibility. Many of the articles did not present nor discussed original 
approaches or findings related to TES sustainability. Moreover, some of them were completely based on theory rather than providing recommendations or practical solutions. At this stage, an additional 792 were excluded. This left a total of 46 articles for the literature review, as illustrated in Figure 1.

\section{Literature Review}

In 2015, the United Nations published the 2030 agenda [12] for sustainable development, highlighting a set of goals for the next fifteen years globally. In 1995, Costanza and Patten [13] argued that for the purpose of sustainability assessment, three main aspects should be defined; the system (or sub-system) in which the sustainability is going to be assessed, the duration that the system is going to be sustained, and the time that the system can be evaluated as sustainable. The high fluctuations of product and service demands and the variations in customers' requirements in one hand, and the rapid changes in technologies and regulations, on the other hand, obligate industries to deploy flexible, agile and adaptable manufacturing systems and business strategies. Reconfigurable manufacturing [14,15], product-service systems (PSS) models, and mass customization are some of the most popular approaches for companies to stay competitive. Moreover, sustainable production, operation and service have always been the focus of industries nationally and globally. Over the last decades, many approaches and solutions, such as cleaner production, lean principles and net-zero carbon emission, have been discussed, developed and implemented to address the environmental and socio-economic problems. In the following sections, some of the key sustainability approaches at different stages of a product life-cycle are presented.

\subsection{Design}

Maxwell and Vorst [16] proposed the sustainable product-service development (SPSD) methodology to identify, assess and implement the optimal sustainable solution in product and service development. The SPSD approach illustrates the movement towards sustainability by 'design for $\mathrm{X}$ ' realm and eco-design. Hoffenson et al. [17] argued that 'design for sustainability' requires integrated planning and strategies to simultaneously consider the economic, ecological, and social consequences of products and production processes. They presented some of the sustainability indicators such as the manufacturing cost, fuel consumptions, noise prolusion, and reliability, to design an aircraft engine. Moreover, Fiksel [18] highlighted that resilience in system design has an impact on sustainability. He listed the main characteristics of a resilient system as diversity, efficiency, adaptability and cohesion. He further argued how the resilient characteristics could impact the economy, environment and society.

\subsection{Prepare}

Sustainable manufacturing can be approached through the implementation of Life Cycle Management (LCM). LMC intends to enhance the effectiveness during usage by means of life-cycle assessment (LCA) and LCC [19]. Moreover, green manufacturing is an environmentally sustainable form of manufacturing that includes green design, production and distribution of raw materials, green maintenance and disposal processes which focus on creating less pollution and overall production waste [20]. Additionally, continuous innovation in production and the evolution of machining systems, support manufacturers to adapt to the changes in business strategies and market demands. Some of the innovations are presented by Jurkovic et al. [15] as intelligent and integrated manufacturing systems, rapid prototyping, reconfigurable machines and intelligent factories. Further metrics for sustainable manufacturing are presented by Reich-Weiser, et al. [21] i.e. energy and water utilization, return on investment and material scarcity rate. Bruzzone et al. [22] presented a mathematical model for energyaware scheduling of manufacturing process demands to optimally plan their energy saving for a given schedule.

\subsection{Utilize}

TES plays a vital role in manufacturing and servicing of complex engineering assets by providing the prognosis of run-to-failure and timeto-failure for better decision making on MRO. TES implementation supports the decision-makers to have a more accurate prediction of the remaining life or Remaining Useful Life (RUL) of components $[23,24]$. Some of the key technologies, tools, knowledge and offerings at the 'utilize' stage are discussed in the following sections.

\subsubsection{Condition Monitoring \& Maintenance}

During the operation, health monitoring and Condition-based Maintenance (CBM) is a basic engineering approach to collect the health and maintenance information. These techniques support the decision-makers on a suitable service solution strategy and ultimately to extend assets' life. Sustainable CBM can be achieved by deploying a continuous health monitoring infrastructure and inspection, non-destructive testing (NDT) and 
maintaining the asset health with minimum labour requirement [25]. Moreover, other factors such as innovation in sensors' material, NDT consumables, assembly, disassembly and installation technologies, data assessment, and knowledge architecture influence sustainability.

Sustainable condition monitoring, inspection, and MRO strategy aim to optimize the components' remaining life and minimize the disruption and breakdown costs. The implication of Remote Monitoring Technologies (RMT) in servitization is highlighted by Grubic and Peppard [26]. They presented that the factors which enable the realization of expected outcomes are skills, experience, knowledge, complementary data sources, processes, structures, operations centres, historical data, and presence of in-house knowledge and capabilities. Whereas, a lack of alignment between services and manufacturing strategies could be a barrier. Nezami and Yildirim [27] developed a framework that utilizes the integrated sustainability metrics to select an appropriate maintenance strategy using a fuzzy approach. In their study, a variety of maintenance strategies, such as preventive, failurebased, reliability-centred, condition-based and total productive maintenance strategies are considered [27]. Later, Sari et al. [28] constructed a framework for measuring sustainable maintenance performance where the performance measures are categorized into the corporate, tactical and functional levels. An optimization model of sustainable maintenance strategies under uncertainty for systems, structures, and assets subject to measurable deterioration over their life-cycle is presented by Daneshkhah et al. [29]. They concluded that the optimal maintenance strategy has an integrated impact on sustainability in terms of reducing energy consumption, reducing the cost of maintenance, and aligning the support policies with social aspects of sustainability.

\subsubsection{Servitization}

Servitization and the relatively new trend of PSS customization are emerging to stimulate a change in the current production and operation patterns and toward sustainable practices [30]. Servitization has been well-known as an environmental sustainability approach to design business models [31]. The combination of a mass customization approach and PSS potentially enhances the sustainability of business models. Hankammer and Steiner [32], however, concluded that this effect is highly dependent on the industry. Sustainable servitization aims to provide customers with a result/outcome rather than a physical product or a functional service e.g. product availability, and mobility, without requiring the customers to own or buy a product, a car or a fuel, in order to get that result [33]. Some of the sustainability effects of PSS are presented by Schröter et al. [34] such as higher equipment availability and utilization, access to customer process know-how, extended equipment life, the lower total cost of ownership, efficiency in energy and material consumptions, and higher reliability and flexibility in service planning. Moreover, a design framework for sustainable PSS is proposed by Song and Sakao [35], which provides an end-to-end modular PSS solution for PSS customization from requirement identification to requirement fulfillment. In a more recent study, Erkoyuncu, et al. [36] developed an effective uncertainty based framework for sustainable Industrial PSS transformation to assist in achieving increased sustainability within the context of IPS2.

Some of the economic indications for sustainable PSS models are the economic growth of businesses through natural energy consumptions, productivity rather than labour intensity, opportunities of mass customization, and applications of information technologies. The social implication of PSS and mass customization can be the balance in labour utilization and skill requirements between manufacturing and service. Intelligent knowledge management systems and web services have enabled e-Maintenance to emerge as a powerful framework to support industrial maintenance and asset management practices [37]. Smart maintenance initiatives for intelligent decision support evolved from $\mathrm{CBM}$ and prognostic and have led to the emaintenance paradigm and the integration of IoT and Cloud-based solutions [38], and autonomous maintenance [39].

\subsubsection{Industry 4.0}

Furthermore, development of Industry 4.0 and smart technologies, such as artificial intelligence, big data analytics, cyber-physical system, cloud computing, Internet of Things (IoT) and Digital Twin (DT) significantly advanced the development of sustainable smart manufacturing and services throughout a product life-cycle [40,41]. Application of Augmented Reality (AR) in supporting maintenance operations [42] and knowledge transfer in maintenance [43] have been highlighted in the literature. Recently, Fernández del Amo et al. [44] argued that the variations in the level of experience and knowledge of expert maintainers and technicians when using AR technology cause communication errors. To address this issue, they proposed a structured-message authoring framework for AR in order to enhance the efficiency of AR-based remote diagnosis services. Furthermore, the authors developed an adaptive DT design framework that uses ontologies within complex engineering systems 
to enable co-evolution across the asset life-cycle [45].

\subsection{Retire}

Remanufacturing is one of the most viable product end-of-life (EOL) management strategies. Diallo et al. [46] discussed the models of quality, reliability, maintenance and warranty for remanufacturing, in a closed-loop supply chain with reverse logistics. They proposed five main areas for future research in remanufacturing as tracking products quality and reliability after recovery, elaborating warranty policies based on consumer preferences and needs, disassembly and optimal replacement strategies for refurbished products, inspection, burn-in and maintenance strategies for second-hand products, and risk, safety and hazards models for remanufacturing. The effect of remanufacturing and PSS integration on sustainability was studied by Fadeyi et al. [47]. They emphasized that the modular architecture in product development is an effective technique that improves the product life-cycle management in terms of simplifying products' disassembly, and therefore improving products' serviceability and cleaning processes.

Circular Economy is a sustainable economic business model that focuses on eliminating waste and the continual use of resources. In such a system, sustainable economic growth can be achieved by reducing the use of natural resources, reducing the emission level of manufacturing and operations, reducing material losses/waste, increasing renewable and recycled resources, maximizing the utility and durability of products, creating local jobs at all skill levels, and creating and distributing the added value [48]. Romero and Rossi [49] demonstrated the compatibility of circular economy and lean principles in the context of PSS. They argued that the integration of the two leads to enhanced customer-oriented solutions that minimize resource consumptions and maximize the value to the end-user.

\section{TES Opportunities in Integrated Sustainability}

Based on the literature review presented in Section 3, a mind map (Figure 2.) has been developed to demonstrate a holistic view of TES opportunities in integrated sustainability, and throughout a product life-cycle. TES opportunities at each stage are presented. The TES opportunities that can be applied to all the life-cycle stages are presented at the centre of the mind map. The identified opportunities were covered in detail in Section 3.

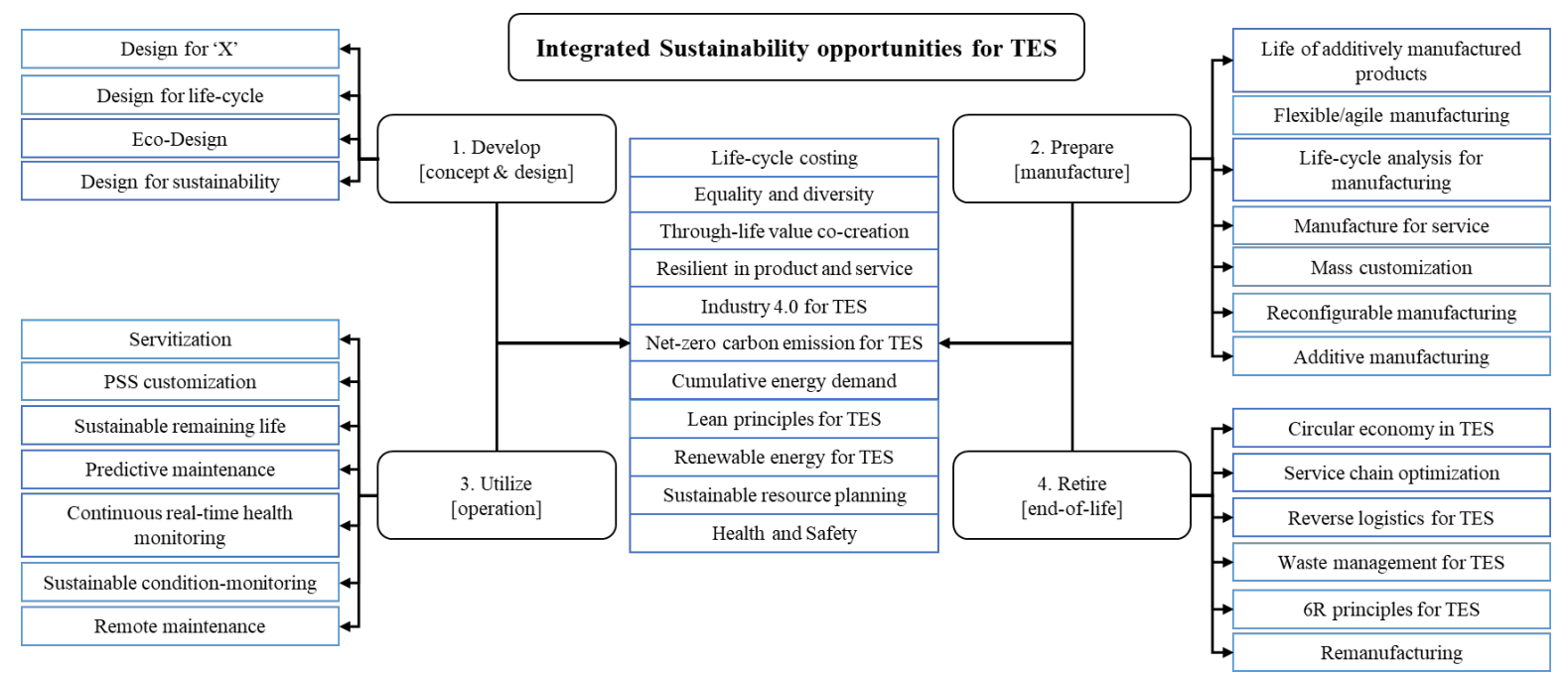

Figure 2. TES opportunities in integrated sustainability over the product life-cycle

The authors found it challenging to map the TES opportunities against the triple bottom lines since there are so many overlaps between the opportunities and their sustainability impacts. Therefore, the mind map has been developed with respect to the TES opportunities at each product life- cycle stages, namely develop, prepare, utilize and retire. Nevertheless, Table 1 summarizes some of the TES opportunities based on their sustainability impacts on TBL. 
9th International Conference on Through-life Engineering Service

3-4 November 2020, Cranfield UK

Table 1: TES opportunities in integrated sustainability

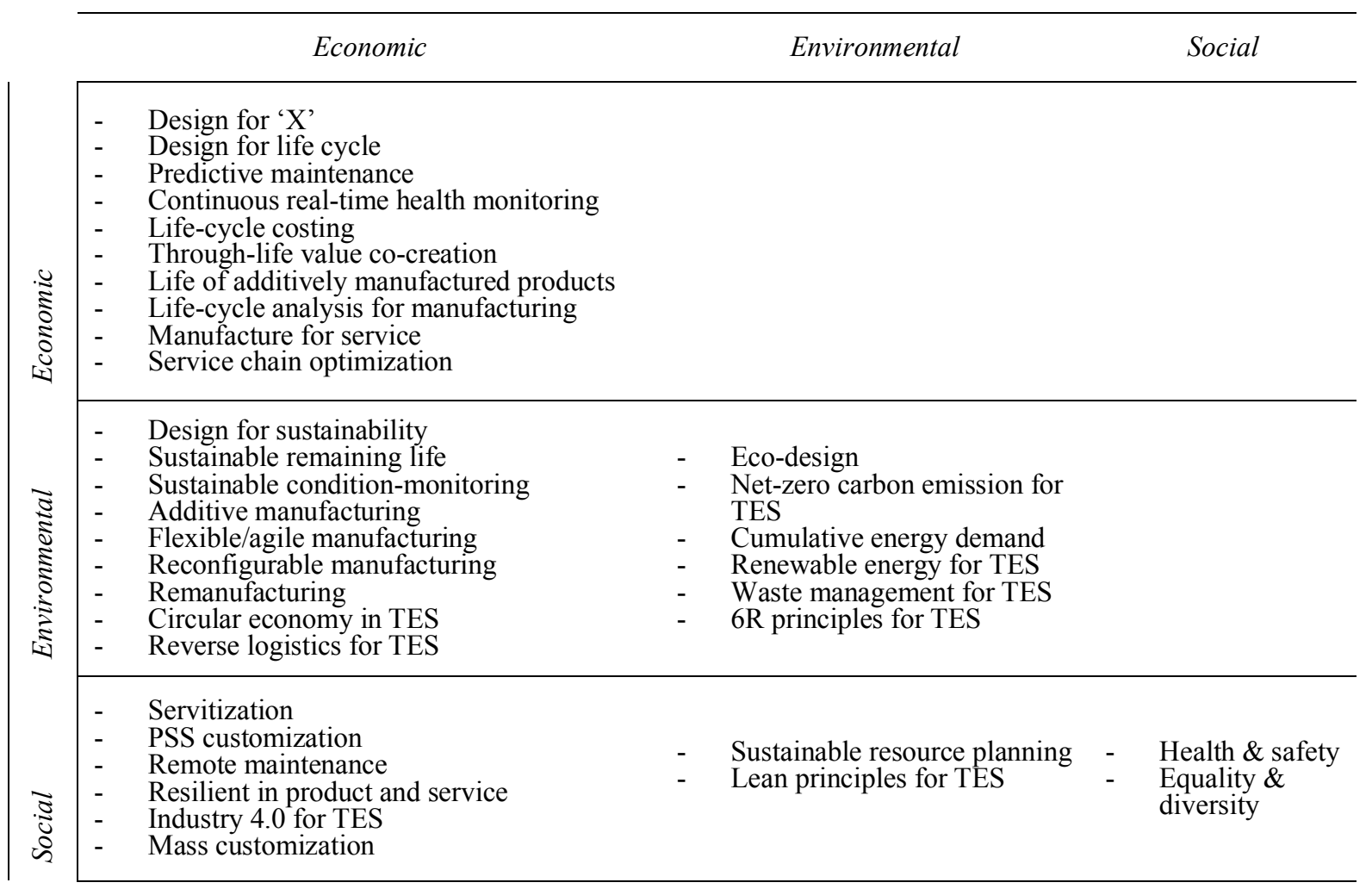

\section{Conclusion and Recommendation}

TES integrates manufacturing, engineering and technology and delivers customer value throughout the product life-cycle with new service-based business models. In contrast to the traditional research in product life-cycle sustainability, TES is therefore capable of providing robust sustainability in a more integrated and holistic manner. This robustness can be achieved by the inherent continuous feedback of experience in TES that informs the design of the next iteration or upgrade of the complex engineering asset and support assets.

This study aimed to present a holistic mind map of TES opportunities in integrated sustainability with environmental, social, economic pillars and throughout a product life-cycle. The systematic review methodology was adopted to select the relevant literature and to determine the research scope in the field. The TES opportunities mind map was then developed based on the synthesis of the 46 reviewed documents including 25 journal articles, 9 conference papers, 3 book chapters and 9 other scholarly documents. Base on Table 1 and as it was expected, the majority of the current and potential TES opportunities relate to economic sustainability, with very limited opportunities for the social dimension. Moreover, considering Figure 2, most of the current TES sustainability approaches focus on the 'prepare' and 'utilize' stages. Therefore, this study provides the following recommendations for future research:

- Although the 'design for ' $X$ ' has been discussed in the literature with the focus on finding the optimum design for products and services, future works should investigate the 'design for ' $\mathrm{X}$ ' over the entire product life-cycle i.e. 'design for service', 'design for manufacturing/ assembly'; 'design for end-of-life'; 'manufacture for service', 'manufacture for end-of-life', 'design service for end-of-life'.

- TES mostly focuses on the economic impacts of inspection, monitoring, and MRO tasks. Further research should focus on the social and environmental aspects; e.g. estimation of the remaining sustainable life of components and designing environmentally and socially friendly tools and technologies for TES activities.

- A wide range of IT and digital technologies are being deployed in the context as a result of I4.0 advancements. Future studies should further investigate 'how I4.0 can be environmentally friendly' and 'what are the social impacts, e.g. human factors, 'human-machine interactions'.

- Further studies can be carried out on the service design for sustainably manufactured products, e.g. design service for additively manufactured products.

- LCC for PSS has been the focus on many studies with a high emphasis on profitability. 
However, future research should focus on LCA for PSS, where the environmental impacts of PSS solution should be assessed and evaluated.

- Considering Table 1, it can be noted that the identified social and social-environmental opportunities of TES are less investigated. Further research should focus on these aspects.

- Further works should be carried out to detail the TBL metrics for TES and their impacts on assets' availability, reliability, quality and cost.

The further work would be focused on validating the proposed TES opportunities mind map and providing a detailed framework for implementing the TES opportunities.

\section{Acknowledgements}

This research is supported by the Through-life Engineering Services Centre at Cranfield University.

\section{References}

[1] Brundtland GH. Report of the World Commission on Environment and Development Our Common Future. Oslo, Norway: 1987. doi:10.9774/gleaf.978-1907643-44-6_12.

[2] Elkington J. Towards the sustainable corporation: Win-win-win business strategies for sustainable development. Calif Manage Rev 1994;36:90-100.

[3] Elkington J. Partnerships from cannibals with forks: The triple bottom line of 21 st-century business. Environ Qual Manag 1998;8:37-51. doi:10.1002/tqem.3310080106.

[4] Farsi M, Hosseinian-Far A, Daneshkhah A, Sedighi T. Mathematical and Computational Modelling Frameworks for Integrated Sustainability Assessment (ISA). Strateg. Eng. Cloud Comput. Big Data Anal., Springer International Publishing; 2017, p. 3-27. doi:10.1007/978-3-319-52491-7_1.

[5] Hosseinian-Far A, Jahankhani H. Quantitative and Systemic Methods for Modeling Sustainability. Green Inf. Technol. A Sustain. Approach, Elsevier Inc.; 2015, p. 83-92. doi:10.1016/B978-0-12-8013793.00005-X.

[6] Kloepffer W. Life cycle sustainability assessment of products (with Comments by Helias A. Udo de Haes, p. 95). Int J Life Cycle Assess 2008;13:89-95. doi:10.1065/lca2008.02.376.

[7] Aerospace Technology Institute. Through-Life Engineering Services technology strategy for the UK Aerospace Sector. 2017.

[8] BSI. PAS 280: 2018 : Through-life engineering services - Adding business value through a common framework - Guide. UK: 2018.

[9] Benoit C, Mazijn B, United Nations Environment Programme., CIRAIG., Interuniversity Research
Centre for the Life Cycle of Producs P and S, Canadian Electronic Library. Guidelines for social life cycle assessment of products. 2013.

[10] United Nations Environmental Program (UNEP). Note 12: Towards a L ife C ycle $\mathrm{S}$ ustainability $\mathrm{A}$ ssessment. 2011. doi:DTI/1412/PA.

[11] Senechal O. Research directions for integrating the triple bottom line in maintenance dashboards. J Clean Prod 2017;142:331--342. doi:10.1016/j.jclepro.2016.07.132.

[12] UNITED NATIONS. TRANSFORMING OUR WORLD: THE 2030 AGENDA FOR SUSTAINABLE DEVELOPMENT UNITED NATIONS UNITED NATIONS. 2015.

[13] Costanza R, Patten BC. Defining and predicting sustainability. Ecol Econ 1995;15:193-6. doi:10.1016/0921-8009(95)00048-8.

[14] Koren Y, Heisel U, Jovane F, Moriwaki T, Pritschow G, Ulsoy G, et al. Reconfigurable manufacturing systems. CIRP Ann - Manuf Technol 1999;48:527-40. doi:10.1016/S0007-8506(07)63232-6.

[15] Jurkovic M, Jurkovic Z, Mahmic M, Karabegovic E. Machining and Manufacturing Systems Evolution. Trends Dev Mach Assoc Technol 2008:85-8.

[16] Maxwell D, Van der Vorst R. Developing sustainable products and services. J Clean Prod 2003;11:883-95. doi:10.1016/S0959-6526(02)00164-6.

[17] Hoffenson S, Forslund A, Söderberg R. Sustainabilitydriven tolerancing and design optimization of an aircraft engine component. ASME Int Mech Eng Congr Expo Proc 2013;12.

[18] Fiksel J. Designing Resilient, Sustainable Systems. Environ Sci Technol 2003;37:5330-9. doi:10.1021/es0344819.

[19] Westkampe E, Alting L, Arndt G. Life cycle management and assessment: approaches and visions towards sustainable manufacturing. Proc Inst Mech Eng Part B J Eng Manuf 2001;215:599--626.

[20] Orji I, Wei S. A detailed calculation model for costing of green manufacturing. Ind Manag Data Syst 2016;116:65-86. doi:10.1108/IMDS-04-2015-0140.

[21] Reich-weiser C, Vijayaraghavan A, Dornfeld DA. METRICS FOR SUSTAINABLE

MANUFACTURING. Proc. 2008 Int. Manuf. Sci. Eng. Conf., Evanston, Illinois, USA: ASME; 2008.

[22] Bruzzone AAG, Anghinolfi D, Paolucci M, Tonelli F. Energy-aware scheduling for improving manufacturing process sustainability: A mathematical model for flexible flow shops. CIRP Ann - Manuf Technol 2012;61:459-62. doi:10.1016/j.cirp.2012.03.084.

[23] Okoh C, Roy R, Mehnen J, Redding L. Overview of Remaining Useful Life prediction techniques in Through-life Engineering Services. Procedia CIRP 2014;16:158-63. doi:10.1016/j.procir.2014.02.006.

[24] Kumar A, Shankar R, Thakur LS. A big data driven sustainable manufacturing framework for conditionbased maintenance prediction. J Comput Sci 
2018;27:428-39. doi:10.1016/j.jocs.2017.06.006.

[25] Sumitro S, Wang ML. Sustainable structural health monitoring system. Struct Control Heal Monit 2005;12:445-67. doi:10.1002/stc.79.

[26] Grubic T, Peppard J. Servitized manufacturing firms competing through remote monitoring technology An exploratory study. J Manuf Technol Manag 2016;27:154-84. doi:10.1108/JMTM-05-2014-0061.

[27] Nezami FG, Yildirim MB. A sustainability approach for selecting maintenance strategy. Int J Sustain Eng 2013;6:332-43. doi:10.1080/19397038.2013.765928.

[28] Sari E, Shaharoun AM, Ma'aram A, Mohd Yazid A. Sustainable maintenance performance measures: A pilot survey in Malaysian automotive companies. Procedia CIRP 2015;26:443-8. doi:10.1016/j.procir.2014.07.163.

[29] Daneshkhah A, Hosseinian-Far A, Chatrabgoun O. Sustainable maintenance strategy under uncertainty in the lifetime distribution of deteriorating assets.

Strateg. Eng. Cloud Comput. Big Data Anal., Springer International Publishing; 2017, p. 29-50.

doi:10.1007/978-3-319-52491-7_2.

[30] Coelho PS, Henseler J. Creating customer loyalty through service customization. Eur J Mark 2012;46:331-56. doi:10.1108/03090561211202503.

[31] Baines TS, Lightfoot HW, Evans S, Neely A, Greenough R, Peppard J, et al. State-of-the-art in product-service systems. Proc Inst Mech Eng Part B J Eng Manuf 2007;221:1543-52. doi:10.1243/09544054JEM858.

[32] Hankammer S, Steiner F. Leveraging the sustainability potential of mass customization through product service systems in the consumer electronics industry. Procedia CIRP 2015;30:504-9. doi:10.1016/j.procir.2015.03.007.

[33] Roy R. Sustainable product-service systems. Futures 2000;32:289-99. doi:10.1007/978-3-319-70223-0_3.

[34] Schröter M, Gandenberger C, Biege S, Buschak D. Assessment of the Sustainability Effects of ProductService Systems. Proc 2nd CIRP IPS ${ }^{2}$ Conf IPS $^{2}$ 2010) 2010:67-74.

[35] Song W, Sakao T. A customization-oriented framework for design of sustainable product/service system. J Clean Prod 2017;140:1672-85. doi:10.1016/j.jclepro.2016.09.111.

[36] Erkoyuncu JA, Roy R, Shehab E, Durugbo C, Khan S, Datta P. An effective uncertainty based framework for sustainable industrial product-service system transformation. J Clean Prod 2019;208:160-77. doi:10.1016/j.jclepro.2018.09.182.

[37] Emmanouilidis C, Jantunen E, Gilabert E, Arnaiz A, Starr A. e-Maintenance update: the road to success for modern industry. Proc. 24th Int. Congr. Cond. Monit. diagnostics Eng. Manag., 2011.

[38] Turner CJ, Emmanouilidis C, Tomiyama T, Tiwari A, Roy R. International Journal of Computer Integrated Manufacturing Intelligent decision support for maintenance: an overview and future trends Intelligent decision support for maintenance: an overview and future trends 2019 . doi:10.1080/0951192X.2019.1667033.

[39] Durazo-Cardenas I, Starr A, Turner CJ, Tiwari A, Kirkwood L, Bevilacqua M, et al. An autonomous system for maintenance scheduling data-rich complex infrastructure: Fusing the railways' condition, planning and cost. Transp Res Part C Emerg Technol 2018;89:234-53. doi:10.1016/j.trc.2018.02.010.

[40] Farsi M, Daneshkhah A, Hosseinian-Far A, Jahankhani H, editors. Digital Twin Technologies and Smart Cities. Cham: Springer International Publishing; 2020. doi:10.1007/978-3-030-18732-3.

[41] Hosseinian-Far A, Ramachandran M, Sarwar D. Strategic Engineering for Cloud Computing and Big Data Analytics. Strateg Eng Cloud Comput Big Data Anal 2017:1-226. doi:10.1007/978-3-319-52491-7.

[42] Palmarini R, Erkoyuncu JA, Roy R, Torabmostaedi H. A systematic review of augmented reality applications in maintenance. Robot Comput Integr Manuf 2018;49:215-28. doi:10.1016/j.rcim.2017.06.002.

[43] Fernández del Amo I, Erkoyuncu JA, Roy R, Palmarini R, Onoufriou D. A systematic review of Augmented Reality content-related techniques for knowledge transfer in maintenance applications. Comput Ind 2018;103:47-71. doi:10.1016/j.compind.2018.08.007.

[44] Fernández del Amo I, Erkoyuncu J, Vrabič R, Frayssinet R, Vazquez Reynel C, Roy R. Structured authoring for AR-based communication to enhance efficiency in remote diagnosis for complex equipment. Adv Eng Informatics 2020;45:101096. doi:10.1016/j.aei.2020.101096.

[45] Erkoyuncu JA, del Amo IF, Ariansyah D, Bulka D, Vrabič R, Roy R. A design framework for adaptive digital twins. CIRP Ann 2020. doi:10.1016/j.cirp.2020.04.086.

[46] Diallo C, Venkatadri U, Khatab A, Bhakthavatchalam $\mathrm{S}$. State of the art review of quality, reliability and maintenance issues in closed-loop supply chains with remanufacturing. Int J Prod Res 2017;55:1277-96. doi:10.1080/00207543.2016.1200152.

[47] Fadeyi JA, Monplaisir L, Aguwa C. The integration of core cleaning and product serviceability into product modularization for the creation of an improved remanufacturing-product service system. J Clean Prod 2017;159:446-55. doi:10.1016/j.jclepro.2017.05.083.

[48] Corona B, Shen L, Reike D, Rosales Carreón J, Worrell E. Towards sustainable development through the circular economy-A review and critical assessment on current circularity metrics. Resour Conserv Recycl 2019;151:104498. doi:10.1016/j.resconrec.2019.104498.

[49] Romero D, Rossi M. Towards Circular Lean ProductService Systems. Procedia CIRP 2017;64:13-8. doi:10.1016/j.procir.2017.03.133. 
2020-10-26

\title{
Toward an integrated sustainability
} assessment in through-life engineering services

\author{
Farsi, Maryam
}

Elsevier

Farsi M, Erkoyuncu JA. (2020) Toward an integrated sustainability assessment in through-life engineering services. In: TESConf 2020 - 9th International Conference on Through-life Engineering Services, 3-4 November 2020, Virtual Event: Host: Cranfield University https://doi.org/10.2139/ssrn.3718041

Downloaded from Cranfield Library Services E-Repository 